\title{
De políticos y política: profesionalización y calidad en el ejercicio público
}

\author{
Manuel Alcántara Sáez
}

\section{Resumen}

El presente artículo discute un aspecto fundamental de la representación política: la calidad de la política en sistemas donde los políticos tienen un carácter claramente profesional. Plantea los requisitos que debe cumplir el político profesional en el terreno de su dedicación y de la remuneración que percibe, y formula un modelo ideal de los elementos constitutivos de un político de calidad, con especial interés en el proceso formativo que integra la carrera de un político.

\begin{abstract}
This article discusses a fundamental aspect of political representation: the relationship between the quality of politics and politicians in those systems where politicians are of a decidedly professional orientation. It establishes the requirements that a professional politician must meet in terms of time commitment and wages, proposing an ideal model of the elements that create a high quality politician, focusing particularly on the formative process involved in a political career.
\end{abstract}

Palabras clave: Calidad de la política, profesionalización, políticos, calidad de los políticos Key words: Quality of politics, professionalization, politicians, quality of politicians

* Catedrático de Ciencia Política de la Universidad de Salamanca, e investigador en el Instituto de Iberoamérica de dicha Universidad. 


\section{Introducción}

Un asunto cuyo estudio ha cobrado relevancia en los últimos tiempos, es el de la profesionalización de la política. ${ }^{1}$ Esto se debe, en gran medida, a dos circunstancias: el desarrollo en el mundo del trabajo del concepto de profesión, y el avance de la democracia representativa en sociedades cada vez menos segmentadas. Es un hecho evidente que el número de hombres y mujeres que tienen a la política como profesión habitual, ha crecido enormemente en los últimos años. El impulso de diferentes instituciones en el proceso de expansión de la democracia representativa, ha hecho posible este escenario, donde la política conjuga más que nunca las dos máximas weberianas de vivir "para" ella y de vivir "de" ella. La partidización de la política, el desarrollo de esquemas descentralizadores, y la creación de instancias supranacionales, conllevan un notable incremento de puestos por los que compiten quienes entran en la política, y hacen posible que la misma se convierta en una actividad de por vida. En este marco, no es inimaginable la existencia de carreras longevas que moldean los supuestos básicos de la representación política, de manera que se genera de manera inevitable una tensión entre los políticos como representantes y como gestores. La profesionalización se constituye, así, en un hecho dado.

Este nuevo escenario supone un reto intelectual para el estudioso, quien además se erige en una suerte de reivindicador de las investigaciones que se centran en el retorno del actor. Las instituciones han supuesto un centro de atención muy relevante en las últimas décadas; su conceptualización en reglas tanto formales como informales, ha tenido un éxito notable en la interpretación y explicación de la realidad política. Sin embargo, las instituciones funcionan en la medida en que existen individuos: aquéllas moldean el comportamiento de éstos, imponiéndoles restricciones y dándoles incentivos; pero a su vez los actores modifican la configuración y el sentido de las instituciones. Por otra parte, los individuos desarrollan relaciones entre ellos que configuran redes que se convierten en recursos adicionales.

La pretensión de este retorno al actor debe tener en cuenta dos aspectos de sumo interés. El primero se refiere a la exigencia de no dejar de lado la relación existente entre el político y el régimen en el que se mueve, tanto en el momento presente como en relación con los legados históricos que pudieran existir. Políticos que iniciaron su carrera bajo dictaduras, se mueven después en escenarios democráticos en los que proyectan sus legados del

1 Las ideas que se recogen en este texto se encuentran más desarrolladas en Alcántara (2012). 
pasado. El segundo tiene que ver con el significado del término profesional en distintos momentos y lugares. Es un lugar común de la hora presente ligar a este término las ideas de dedicación, remuneración adecuada, competencia en ciertas habilidades y fijación de determinadas tareas de acuerdo con lo estipulado por las leyes y la práctica política.

Hoy, los profesionales de la política están en buena medida presentes en los partidos, desde los que saltan a los espacios de representación. La relación entre ambos no deja de ser compleja y en ocasiones uno impone su designio al otro. El modelo ideal de democracia representativa ha enfatizado la idea de que los políticos son reclutados, formados y proyectados hacia las instituciones por los partidos; pero esto no siempre es así. La propia dinámica democrática, junto con otros factores de índole social, cultural o económica, posibilita modelos diferentes en los que los políticos pueden configurar carreras independientes. Pero en ambos casos, y a pesar de su amplia y reiterada connotación negativa en medios populares, la lógica de la profesionalización no deja de estar presente.

Este desempeño de una forma peculiar de profesionalización, se ve entonces animado por el hecho de que el político, durante su vida activa, posee y manifiesta un bagaje más o menos amplio de activos personales bajo la figura de atributos y cualidades que se engarzan con aspectos institucionales del sistema político. Todo ello conforma una suerte de capital político. Esta relación entreverada se da en un proceso de retroalimentación que es el motor de una carrera especial, y muy diferente de la que se da en el ámbito de otras profesiones; carrera guiada en buena parte por la ambición y en la que se siguen pautas definidas, bien sea por la elección o bien por la designación, o por una combinación de ambas.

La idea es que el político, a lo largo de todo el proceso, capitaliza un escenario que va variando en el tiempo, con miras a progresar en su andadura y fin de culminar ésta lo más satisfactoriamente posible para sus intereses. Éstos pueden ser de orden material, de orden espiritual, o una combinación de ambos. Los primeros traducen la búsqueda egoísta de una sensible mejora de su situación económica, mientras que los segundos buscan dar cumplida satisfacción a su vocación inicial altruista de servicio y compromiso social, o pueden reflejar la búsqueda de otros propósitos de carácter hedonista o incluso megalómano.

Por consiguiente, en el inicio de toda carrera política se conjugan los activos individuales de que el político dispone como su capital original, con los mecanismos institucionales de entrada, que pueden tener carácter partidista o no. Cualquier individuo que entra en política, con independencia de sus elementos fenotípicos, tiene un capital que puede proceder de 
cinco fuentes que no son incompatibles: la primera es estrictamente política y se deriva del proceso de investidura que le otorga su adscripción a una formación política concreta, cuyo interés fundamental radica en reclutar a personal para sus fines; la segunda proviene del nivel de formación adquirida y posiblemente completada con cierta experiencia profesional en instancias laborales, ${ }^{2}$ la cual termina dotándole de la expertise técnica que le abre la puerta del mundo de la política por su funcionalidad; la tercera se deriva de la posesión de altas cotas de popularidad, debidas a la práctica de una actividad cuya amplia exposición social es similar a la de los artistas, los deportistas y los comunicadores sociales, y cuya imagen es un eficaz reclamo a la hora de la captura de los votos; la cuarta procede del legado familiar, es decir, de la pertenencia a una familia cuyos antecedentes y experiencia en la vida política proveen al candidato de símbolos, contactos y redes; y la última se deriva de la posesión de una renta económica suficiente, la cual le permite afrontar los costos de entrada, básicamente de la campaña electoral.

Los individuos que poseen alguno de estos tipos de capital, terminan entrando en la política a través de la socialización en la vida partidista, en cuyo seno siguen una carrera más o menos canónica diseñada por el partido y subiendo un escalón tras otro, o son cooptados, tanto por el partido como por un líder con trayectoria propia, para puestos concretos, lo que les permite ascender de golpe en el escalafón gradual en que se mueven los anteriores. Paralelamente a estos dos mecanismos de entrada, hay un tercero reservado normalmente para quienes no poseen un capital original estrictamente político y cuyo perfil es individual-electoral; se trata de personas con un activo técnico ${ }^{3}$ como único bagaje, y que entran en la política mediante procesos electorales, al igual que sucede con quienes su activo es de orden popular. ${ }^{4}$ Después se encuentra el desarrollo de una carrera

2 Me refiero a ámbitos diferentes, como pueden ser, entre otros, la ingeniería, la medicina, las finanzas, la administración de empresas, o la propia abogacía.

3 El ejemplo más conocido en América Latina en los últimos años de político que inicia su carrera de esta manera, es el del ingeniero peruano Alberto Fujimori, presidente entre 1990 y 2001.

4 Cantantes, deportistas y periodistas han entrado en la política, la mayoría de las veces, cooptados por los partidos; éste es el caso de los cantantes Rubén Blades, ministro de Turismo en Panamá entre 2004 y 2009; de Gilberto Gil en Brasil, ministro de Cultura entre 2003 y 2008, y de Susana Baca, ministra de Cultura de Perú entre agosto y diciembre de 2011; también podemos mencionar al automovilista Carlos Reutemann, dos veces gobernador y tres veces senador en Argentina; y al comunicador televisivo Mauricio Funes, presidente electo en El Salvador en 2009. Un caso diferente es el del presidente de Haití, electo en 2011: el cantante Michel Martelly, cuya trayectoria política se inicia, no por cooptación partidista, sino por iniciativa individual, ya que se presentó por sí solo y directamente a las elecciones. En España, el actor Toni Cantó, 
política en función del uso de determinadas estrategias de capitalización de la posición que se tiene en la escena pública, y del uso de determinados mecanismos de continuidad. Una vez iniciada su carrera política, los individuos que quieren tener una trayectoria más dilatada en el tiempo, despliegan tres posibles estrategias de capitalización de su posición: mantenerse fieles al partido en el que comenzaron su andadura, a la espera de ir quemando sucesivas etapas, conseguir experiencia y ganar cuotas de poder; cambiarse a otro partido que les ofrezca mejores perspectivas de progreso y donde se sientan más cómodos, es decir, donde estén más acordes con los postulados ideológico-programáticos compartidos; $y$, por último, mantenerse independientes de toda oferta partidista. Los mecanismos de continuidad son asimismo tres: la incorporación a procesos electorales gracias a los cuales la carrera se va consolidando en el terreno representativo; la designación en puestos de confianza, lo que supone una minusvalía de la autonomía; y una combinación de ambas, lo que viene a significar el salto de puestos del Legislativo a otros del Ejecutivo.

Este artículo pretende abrir una discusión acerca de un aspecto sustantivo de la representación política: el de su calidad, la cual es un concepto de carácter claramente multidimensional. La premisa es sencilla: la calidad de los políticos debería incidir en la calidad de la política. En la medida en que los políticos son profesionales de la política, la calidad de su desempeño puede analizarse, como ocurre en otros ámbitos profesionales, en función de patrones que abarcan diversas pautas y componentes de la profesionalización. Ésta se configura, así, como un elemento central y se erige en una propuesta de investigación futura muy relevante. En primer lugar, en este trabajo se discuten aspectos relativos a la relación entre la calidad de la política y la de los políticos; después se analizan los elementos que constituyen una carrera política típica, y luego se plantean cuáles podrían ser las cualidades constitutivas de un político de calidad. Y puesto que una de las cualidades más significativas es el componente formativo, se lleva a cabo una propuesta del mismo, y se concluye con una recapitulación de lo abordado en el artículo.

\section{Calidad de la política y calidad de los políticos}

Si cualquier actividad requiere de profesionales de calidad, no es menor la exigencia en el seno de la política. Ahora bien, los estudios sobre la calidad

que milita en las filas del partido Unión Progreso y Democracia, fue elegido diputado en noviembre de 2011. 
de la política han avanzado en los últimos años divorciados de la atención a la existencia de políticos de calidad. Pareciera que no hubiera relación alguna entre políticos y política; sin embargo, el éxito de ésta se vincula con su material humano, que debería ser de alta o, al menos, de suficiente calidad. ${ }^{5}$ Por lo tanto, el hecho deplorable de que la literatura producida en la última década en torno a la calidad de la democracia, ${ }^{6}$ haya prestado tan escasa atención a la calidad del papel desempeñado por los políticos, debe subsanarse, más aún cuando existe conciencia del carácter multidimensional del concepto.

Sólo marginal o incidentalmente, la calidad de los políticos es considerada, en la dimensión de los resultados del modelo de análisis propuesto, en los estudios relativos a la capacidad de respuesta (responsiveness) del régimen político; en ellos se da cabida tímidamente a la actuación de los ejecutores políticos responsables de las políticas públicas. ${ }^{7}$ Sólo muy recientemente la inquietud de los estudiosos está girando hacia la necesaria relación existente entre la calidad de la democracia y la de los políticos. Se reivindica el papel de los políticos profesionales en los procesos de democratización, ${ }^{8}$ se denuncia la responsabilidad de los malos políticos en los problemas de la democracia representativa, ${ }^{9}$ y se vincula la calidad de la democracia deliberativa con la calidad de los representantes. ${ }^{10}$ Los políticos surgen del seno de la sociedad en que viven, están marcados por los valores compartidos y reinantes en la misma, por lo que en gran medida su actuación no deja de traducir los rasgos o señas de identidad que la definen. ${ }^{11}$ Los legados históricos, sociales y culturales siempre tienen que

5 Ésta era la primera de las cuatro condiciones que Schumpeter (1947: 290) estableció para que la democracia fuera un éxito.

6 O’Donnell, Vargas e Iazzetta (2004); Diamond y Morlino (2005); y Levine y Molina (2011).

7 Powell (2005).

8 Schmitter (2010: 26-27) señala: “La democratización no require precisamente de ciudadanos aficionados sino de políticos profesionales. Hay un mito persistente de que los cargos electos son justo gente corriente que se prestan temporalmente para ser servidores públicos. Los aficionados pueden conducir la lucha contra la autocracia y ocupar cargos en la cúspide al comienzo de la transición, pero pronto harán sitio a los políticos profesionales. Los políticos hoy necesitan muchos recursos partidistas y personales para ganar las elecciones, requieren conocimiento especializado para el rendimiento de cuentas de los tecnócratas, y deben rodearse con expertos en opinión pública para permanecer en el cargo" [traducción del autor].

9 Pasquino (2010) indica que "en última instancia, mi valoración es que la calidad de la clase política (y antipolítica) es la responsable del mal funcionamiento del sistema político italiano y de su modelo parlamentario".

10 Bermeo (2003).

11 "Lo fácil en las sociedades donde existe un exiguo arraigo de la responsabilidad individual es echarles siempre las culpas a los dirigentes cuando las cosas nos van mal... Es difícil que haya políticos de baja calidad en una sociedad de ciudadanos exigentes...", Fernando Vallespín. 
ser tenidos en cuenta; ${ }^{12}$ pero es también evidente que los políticos, como profesionales, pueden estar dotados, o no, de ciertos atributos que contribuyan a hacer de su trabajo uno de calidad diferenciada. Cierto, un político de calidad de nada sirve si no encuentra venturosamente a su alrededor un contexto favorable en el que se pueda insertar su actividad. Hay cientos de ejemplos de políticos fracasados, o incluso que terminaron en el mayor de los desastres, a pesar de que cumplían con creces las condiciones que hemos enumerado aquí. A propósito de esto, se sabe que algunos predictores efectivos de la calidad de los candidatos, son: la pertenencia al partido mayoritario, dinero, visibilidad y experiencia, así como el conocimiento del distrito al que representarán; ${ }^{13}$ dichos requisitos coinciden, en gran medida, con el particular concepto de capital político ${ }^{14}$ que poseen los políticos; y aunque este capital varía según el partido en que militan, está integrado por los años de servicio en el partido, los recursos financieros y las redes políticas con que cuentan.

Esta imbricación del político y el medio, se da de manera superlativa en los partidos, que son el nicho natural en el que aquél ha venido desempeñando su actuación. Así pues, la suerte del político se ve en gran medida condicionada por el partido, y la proyección de la calidad intrínseca del político es resultado de las características del partido, tanto en lo relativo a su estructura interna como a su idiosincrasia. Los partidos, en una carrera constante para incrementar su poder, a la vez que consiguen satisfacer la ambición de sus militantes o compañeros de viaje, proyectan su influencia en numerosos ámbitos de la vida pública, siendo la expansión en el terreno de los cargos la más explícita. Es un escenario en el que todos ganan, en el sentido de que los partidos amplían su zona de influencia y los políticos profesionales cuentan con mayor espacio donde llevar a cabo su carrera y satisfacer sus expectativas. Este acaparamiento, que resulta de la acumulación no sólo de asesores sino de puestos en muy diversos ámbitos, fue típico del Estado desarrollista en América Latina en su época dorada, en las décadas de 1960 y 1970. Ahora reverdece al amparo de otros mecanismos,

\footnotetext{
“¿Quiénes son peores, nuestros políticos o los ciudadanos?” El País, Madrid, 26 de diciembre de 2009. Algo que ya aventuró John Stuart Mill al reconocer que la forma apropiada de gobierno para cualquier sociedad, dependía de las capacidades de los ciudadanos.

12 "En cierta ocasión el general Torrijos, ante las constantes quejas de los residentes de los corregimientos en virtud de la desaforada conducta de los representantes de los corregimientos, formuló la siguiente frase lapidaria: 'La comunidad que elige a un pillo es tan pilla como aquél' ", Antonio Saldaña. "No es el Presidente, es la Constitución", La Prensa (Panamá). 3 de septiembre de 2010.

13 Fowler y McClure (1989: 237).

14 Norris (1997: 209).
} 
como los entes reguladores y otras expresiones de la influencia política, donde los partidos tienen cuotas acordadas. Este tipo de profesionalización espuria tiene un doble carácter contradictorio. Por una parte, incrementa casi exponencialmente la necesidad de políticos, cuya mejor preparación es un requisito insoslayable; por la otra, es uno de los fenómenos más perniciosos que vive la democracia representativa, por cuanto la gente lo percibe no sólo como un reparto del botín de los cargos, sino como un acceso preferente a los mismos en nombre de la democracia. El deterioro del sistema político democrático, a principios de la década de 1990, en Italia y Venezuela, países ambos con una elevada presencia de la partidocracia y modelos hasta entonces de desarrollo democrático con un extenso aparato estatal, es una prueba de ello.

La otra cara de la moneda en el escenario político actual, es la transformación registrada en el seno de las élites de algunos países, las cuales están inmersas en un proceso de cambio desde "los profesionales de la política hacia profesionales expertos en cargos políticos" ${ }^{15} \mathrm{El}$ ascenso de expertos tecnócratas es otra forma de profesionalización espuria de la política. A diferencia de los "políticos de cuota" del párrafo anterior, este tipo de políticos basa su autoridad en su conocimiento científico o experto, que tiene un alto grado de aplicabilidad en la acción pública. Si bajo la sombrilla de las cuotas pueden entrar en la política personas mediocres cuya principal virtud es la servil lealtad a quien les designó, el paradigma tecnocrático avala la excelencia de los expertos escogidos; sin embargo, los nuevos mandarines tensionan el carácter democrático del sistema político e introducen una variable más, poco sopesada hasta hoy, a la hora de analizar su calidad.

La profesionalización espuria de la política, implícita en la extensión irrestricta de miles de individuos que entran en la misma mediante mecanismos ajenos por completo a la voluntad popular, es un serio problema, de carácter sistémico, con el que se enfrenta la calidad de los políticos; un problema teórico y global notable, con evidentes implicaciones prácticas. El nivel de descontrol absoluto, la falta de transparencia y, en general, de rendición de cuentas, suponen un lastre con consecuencias negativas difíciles de atajar.

Ahora bien, establecer los estándares capaces de introducir una medición sobre la bondad del quehacer del profesional de la política en cualquiera de estos escenarios, resulta complicado. Aplicar el término calidad en un asunto como el presente, y en la dirección que se propone aquí para el análisis de la calidad de la democracia, requiere recordar la existencia

15 Aguilera y Fuentes (2011: 129). 
de tres significados diferentes de esa palabra, vinculados al procedimiento, el contenido y el resultado. ${ }^{16} \mathrm{Su}$ aplicación, como se verá inmediatamente, no resulta del todo fructífera.

Una parte importante de quienes se dedican a la política, entran en ella mediante procesos electorales competitivos cuya naturaleza requiere de destrezas muy diferentes a las de la subsiguiente actividad de gobierno o de oposición. Ésta es una primera dificultad procedimental que es soslayada con frecuencia; sin embargo, no debe dejarse en el trastero la diferencia existente entre los atributos, ahora de contenido, que se requieren para alcanzar el poder, de los necesarios para su ejercicio. ${ }^{17}$ Un repaso a la discusión recién abordada sobre los atributos de los políticos, evidencia esta situación, puesto que el político "de cuota" requiere de características o cualidades muy diferentes de las del técnico. Además, hay indicios de la existencia de una notable relación entre los políticos profesionales y la estructura de su personalidad; indicios vehementes de que el político profesional se caracteriza por tener una personalidad más dogmática que la del resto de la gente, ${ }^{18}$ lo cual complica el escenario. Si ahora se tiene en consideración el resultado, el mismo varía en función de esta misma disyuntiva; ganar unas elecciones es un excelente resultado, más o menos mejorable en función del tipo de éxito alcanzado. Mantenerse después en el poder por un largo periodo, es también un buen resultado, pero de otra naturaleza. Cumplir el programa, satisfacer las demandas o incluso las variopintas expectativas de la población y resolver problemas, son otros tipos de resultados.

Los primeros años de la mayoría de las carreras políticas, son tiempos marcados por una doble confrontación: en el seno del propio partido y con relación al electorado. Las contiendas vividas en el partido se articulan mediante un mecanismo muy especial donde se entrecruzan destrezas individuales marcadas por la sumisión, la componenda, la solidaridad, la capacidad de trabajo, la inteligencia, en fin, el liderazgo, con dispositivos institucionales que traducen la organización peculiar del partido y el grado diferenciado de estructuras de oportunidad existentes. Después, están los requisitos que demanda toda campaña electoral, entre los que se incluyen algunos de los anteriores, como la energía, la visibilidad mediática, la disciplina y la coordinación. A todo este conjunto variopinto de elementos, se añaden las características de los adversarios, de los electores y de las propias normas que regulan los comicios.

\footnotetext{
16 Diamond y Morlino (2005a: xi).

17 Katz (1966:5).

18 DiRenzo (1967).
} 
Todo ello se deja de lado, en gran parte, cuando se llega al paso siguiente: una determinada instancia de poder, ya sea el Congreso, un ámbito en el Poder Ejecutivo, o un tercer organismo. Allí el quehacer se realiza bajo coordenadas muy distintas, en función de la naturaleza de la institución, del nivel que el político ocupa y de la correlación de fuerzas existente con otros grupos tanto de naturaleza política (el propio partido, los otros partidos) como administrativa (la burocracia en general). Desde siempre, es en este ámbito donde los tratados sobre el buen gobierno y los breviarios de consejo a los príncipes, han puesto su acento. De hecho, la obra de Maquiavelo, que sí se ocupa de las dos vertientes aquí expuestas, concentra mucho más su atención en la segunda; como bien se sabe, el arte de mantenerse en el poder se convierte en el argumento central, por encima de la vocación de servicio transformadora, que termina siendo minoritaria.

Al final, el político profesional es un compendio de ambas fases, y una suma de las distintas etapas de su trayectoria; lo que se conoce de él y de ésta, integra las facetas de la llegada al poder con las de su ejercicio. Procedimiento, contenido y resultado terminan obstinadamente entrelazados, lo cual hace muy difícil establecer con precisión mínima los niveles que debería alcanzar un político profesional de calidad.

\section{La carrera política es una cuestión de dedicación, de tiempo y de dinero}

La idea de carrera se vincula con la dimensión temporal, donde se configura un continuo cronológico definido por el tiempo que se está en la política; una considerable extensión de este lapso se correlaciona positivamente con la mayor socialización del político, ${ }^{19}$ lo que a su vez contribuye a una mayor profesionalización. El tiempo en política puede ser discontinuo, a saltos, o más o menos continuo, o de por vida; es decir, diferencia a los políticos en tres tipos: el personaje cuya presencia en la política es intermitente, con entradas y salidas ocasionales; el que es constante a lo largo de un determinado periodo, y aquel que dedica toda su vida a la actividad política. La ecuación es clara en ambos aspectos: cuanto mayor es la exclusividad o

19 “Después de que una persona ha estado en un partido durante cierto tiempo, en todos los países, al menos en los sistemas democráticos, los contactos sociales, las relaciones de amistad, el reconocimiento personal, la parte lúdica de las campañas se hace más importante. Este descubrimiento sugiere un similitud básica en el proceso de socialización partidista a lo largo de los sistemas", Eldersveld (1989: 11-12). [Traducción del autor] 
el tiempo dedicado a la política, mayor es el nivel de la actividad política. La situación opuesta, que define al político amateur, es la dedicación parcial a la política, es decir, menor tiempo y una intermitente presencia en la misma. El cruce de ambos niveles permite referirse a una matriz de doble entrada con distintas gradaciones, cuya propuesta se recoge en el cuadro 1 y permite ubicar las diferentes situaciones de quienes se dedican a la política.

Cuadro 1. Intensidad y tiempo en la actividad política

\begin{tabular}{llll}
\hline & & \multicolumn{2}{c}{ Tiempo: t1....ti } \\
\cline { 3 - 4 } Dedicación & Intermitente & Continuo & De por vida \\
\cline { 2 - 4 } & & & \\
\hline
\end{tabular}

Este escenario es compatible, desde una visión de largo plazo, con la figura de alguien que esté en la política a todo lo largo de una vida profesional, periodo que puede extenderse aproximadamente cuarenta años en promedio. En esta trayectoria vital caben diferentes modelos.

La intensidad y la extensión del tiempo dedicado a la política, o sea, la exclusiva dedicación a ella y una dilatada experiencia, configuran una carrera política. ${ }^{20}$ Ésta recibe el calificativo de profesional cuando se incorpora a ella la dimensión económica, es decir, el salario y aquellas otras prebendas complementarias que reciben los políticos, como exención de impuestos, bonos de gasolina, billetes de avión, gastos de secretaría y fondos de pensiones, según los casos, que configuran una maraña difícil de conocer. A diferencia de otras profesiones, no se da una relación conflictiva entre la carrera profesional del político y su nivel retributivo, ${ }^{21}$ aunque hay sóli-

20 Para el caso de los parlamentarios, la carrera se moldea de conformidad con la experiencia adquirida en el trabajo en comisiones o en cargos directivos de la Cámara. Este aspecto es utilizado para formalizar una propuesta de índice de profesionalización por cabeza de los diputados (tesis doctoral en curso).

21 A propósito del conflicto de los controladores aéreos acontecido en España a lo largo de 2010 y que tuvo su momento álgido en una huelga salvaje en diciembre de ese año, se puede leer en una entrevista con Manuel Pimentel, árbitro en dicho conflicto, lo siguiente a propósito de la distinción entre salario y carrera profesional: "Había que tomar una decisión importante: la jornada. El salario venía acordado de agosto y no había problema. El salario no fue nunca una prioridad para los controladores. Importaba más la carrera profesional, el sistema de turnos... Pero la empresa debe tener facultades para decidir, así que para determinados puestos la empresa podrá escoger entre quienes cumplen determinados requisitos". (Véase El País. Madrid, de 04.03.11.) Pero además es interesante constatar la posición de algunos sectores de la propia clase política, que llegan a proponer rebajas salariales para su actividad, enviando una señal de cierta popularidad ante la sociedad pero, a la vez, de minusvaloración o depreciación del quehacer político. Es el caso del coordinador de Izquierda Unida en Extremadura, Diego Val- 
das evidencias de que si los políticos están bien pagados, su rendimiento también mejora en casos particulares. ${ }^{22}$

Otra diferencia sustantiva es que los políticos suelen tener la potestad de fijarse su salario a través del propio proceso de elaboración del presupuesto, o mediante la autonomía de los cuerpos colegiados de que forman parte. Esta práctica suele ser objeto de crítica, e incluso llega a generar en ocasiones cierta alarma social; ${ }^{23}$ pero puede compararse, en el ámbito privado, con las prácticas de las grandes empresas, donde los directivos de sus consejos de administración también se fijan sus honorarios, sin someterlos a la aprobación de sus juntas de accionistas. Sin embargo, el caso de los primeros es mucho más grave, por tratarse de dinero público. Además, es un aspecto que no va siempre en la dirección popularmente esperada de medrar con abuso. ${ }^{24} \mathrm{En}$ cuanto a recibir cierta retribución por la actividad política desempeñada, es posible analizar diferentes aspectos de esta práctica. En primer lugar, debe considerarse el grado en que el sujeto depende económicamente de su actividad política, pues puede registrarse la situación extrema de que la totalidad de los ingresos percibidos provengan de la política y los mismos sean inexistentes. Luego está el nivel diferenciador en una escala salarial general, es decir, la comparación con los ingresos de otras profesiones en la gama más alta del mercado laboral, ${ }^{25} \mathrm{O}$

deras, quien propuso aumentar el número de escaños de 109 a 135, y reducir los sueldos de los mismos un $20 \%$, para que el incremento no supusiera ampliar el presupuesto de la Cámara legislativa. (Véase El País, Madrid, de 21.06.11.

22 Besley (2004) lo prueba con un estudio sobre gobernadores en Estados Unidos, pero también señala que no hay una evidencia muy sólida de que el nivel salarial sea lo más importante en la carrera de un político.

23 Una de las primeras crisis que tuvo que afrontar Laura Chinchilla al asumir la presidencia de Costa Rica, fue anular la subida de sueldo de los legisladores que había aprobado la Asamblea Legislativa saliente. En otro sentido, los diputados del Parlamento Europeo han rechazado enfáticamente hacer público un informe secreto realizado por Robert Galvin, jefe de auditoría interna, en el que se daba cuenta de sus gastos realizados, sin justificante alguno, por un importe de poco más de doscientos millones de euros, y ello a pesar de la existencia de una disposición de la Corte de Justica europea, que abogaba por su publicidad debido a "overriding public interest in disclosure". Véase de 14.06 .11 http://www.telegraph.co.uk/news/worldnews/europe/eu/8564124/European-parliament-refuses-to-release-expenses-report.html Así eran las cosas en los primeros momentos del triunfo sandinista en Nicaragua: "Dije en la reunión de gabinete que entre nosotros nadie pedía sueldo, porque todos trabajaban gratis. Y se rieron... Después hubo una mayor regulación en el gobierno, y todos debían tener sueldo. Hicimos que cada uno se pusiera su sueldo, según juzgara la categoría de su trabajo. Cuando presenté nuestro presupuesto en la reunión del Gabinete, era el más bajo del gobierno, y los otros ministros me hicieron una ovación. Era absurdo por austero", Cardenal, 2004: 335.

Un estudio para el año 2000 sobre el sueldo de los gobernadores en Estados Unidos, señalaba que era sesenta veces menor que el del promedio de cualquiera de los 350 directivos de otras tantas compañías mayores del país (véase Besley, 2004: 194). Por otra parte, en 2010 la élite em- 
la comparación con el promedio nacional de ingreso salarial, o con el promedio inferior de ingresos. ${ }^{26}$ Finalmente, se encuentra la propia variación en el seno de la misma clase política, al registrarse la existencia de cargos con niveles salariales muy diferentes de acuerdo, o no, con la escala de la actividad llevada a cabo. ${ }^{27}$

\section{Las cualidades de un político de calidad}

En las consideraciones sobre lo que los políticos deberían hacer, y sobre las cualidades de carácter que les ayudarían a llevar a cabo sus finalidades, concurren intuiciones que entran en conflicto entre sí. ${ }^{28} \mathrm{Al}$ respecto, existen preocupaciones diferentes en diversos sectores; algunos de éstos consideran que los políticos venderían a sus representados a cambio de beneficios personales, o de satisfacer a quienes contribuyeron en sus campañas; otros estiman que lo que venderían los políticos es el bien común, o derechos de las minorías, para satisfacer a determinados sectores del electorado. Se quiere a políticos que sean expertos y, a la vez, simpáticos; que representen los anhelos y los intereses de la gente, aun cuando éstos sean a veces contradictorios; que oigan a la gente en general, no a determinados sectores; que sean representantes del interés general, pero que a la vez enfaticen las demandas del grupo directo a quienes primariamente representan: los

presarial española, compuesta por los consejeros ejecutivos y los altos directivos de las empresas que cotizan en la bolsa del país y que conforman el denominado IBEX, estaba conformada por unas 540 personas que cobraron algo más de un millón de euros de media; es decir, unas diez veces el nivel de ingresos de un número similar de personas que componen la élite política representativa integrante de las Cortes Generales. Por otra parte, el sueldo medio de un consejero ejecutivo de una empresa del Ibex creció $64 \%$ en seis años, a una media de $9 \%$ anual (véase El País, Madrid, 06.03.11).

26 El salario mínimo interprofesional en España para 2010 fue de 633.3 euros mensuales, equivalente a 7600 euros anuales. Véase: http:/ / www.ine.es/jaxi/menu.do?type=pcaxis\&path=/ t22/a063\&file=inebase \&N=\&L= 06.03.11

27 La coalición gubernamental británica se plantea publicar el nombre, empleo y los ingresos de todos los funcionarios cuyo sueldo supere los 69000 euros. De momento se conoce, a través de la Oficina del Consejo de Ministros, que más de 170 altos cargos públicos en Reino Unido tienen salarios superiores al del primer ministro británico (169 000 euros); entre ellos se encuentran al menos 28 personas (cuyo sueldo supera los 178000 euros) que trabajan en el Ministerio de Defensa, y sólo tres en la Secretaría de Transporte. El director ejecutivo de la Oficina de Comercio Justo (OFT, por sus siglas en inglés), John Fingleton, encabeza la lista con un paquete anual - que incluye dietas y beneficios imponibles - de más de 333788 euros. El director ejecutivo del Servicio Nacional de Salud británico (NHS), David Nicholson, cuenta con un salario que supera los 309000 euros, y el jefe de la oficina de Información de la Secretaría de Trabajo y Pensiones, Joe Harley, supera los 295000 euros (véase El País, Madrid, 01-06-2010). 
electores de su circunscripción, o los favorecidos por la línea programática estricta enunciada en la campaña electoral.

Todo esto vuelve a conducir al explícito conflicto entre universalismo y particularismo, que exige una suerte de compromiso permanente entre ambos $^{29}$ y reproduce la tensión weberiana entre vocación (universalismo) y profesión (particularismo). Una necesaria posición intermedia requiere un compromiso que no satanice una posición frente a la opuesta, y que haga los costes del mismo manejables. Es tarea de la ciencia política elaborar el mejor escenario teórico sobre los aspectos de la actividad política que deben considerarse relevantes, con miras a posibilitar una práctica posición intermedia. Una compleja visión que ahora nos permitirá enumerar los elementos que debe reunir un político en el camino hacia una mayor calidad.

Si en términos generales a toda persona profesional se le puede exigir que ejerza su profesión "con relevante capacidad y aplicación", 30 en el terreno de la política ello llevaría a una desagregación de dichos términos. Capacidad es sinónimo de competencia, y podría entenderse como una suma o una combinación de talento y experiencia; mientras que la aplicación podría concebirse como dedicación exclusiva. Pero en el político, como ya se dijo, todo ello varía en función del sitio en que actúe, lo que dificulta el diseño de esquemas generales; si bien la mayoría de la clase política tiene un perfil polifacético, es bajo esta consideración donde debe situarse la relevancia del propio quehacer.

La propuesta que aquí defiendo implica que el político profesional de calidad realice su actividad de manera continua y exclusiva, que posea el mayor talento relevante posible y goce de gran experiencia. Aunque la dedicación total tiende a ser la norma, es muy importante señalar que existe una notable diferencia en términos de género, por cuanto el número creciente de mujeres que se dedican a la política mantiene diferentes actividades en el seno del hogar, lo que vuelve imposible para ellas una dedicación plena a la política. Hecha esta consideración de implicaciones notables a favor de la insoslayable equidad de género, la excelencia se establece en los términos de la relevancia del talento y la experiencia, que admiten un mayor rango de variabilidad. El talento combina las dotes personales innatas, las mixtas y las adquiridas. Por dotes innatas se entienden aquellas específicas que tienen su máxima expresión, aunque no única, en la inteligencia y en la posesión de un mínimo de capacidad física que permita afrontar jornadas interminables, así como hacer frente al estrés que se acumula co-

29 Sabl (2002: 20-54).

30 Quinta acepción de "profesional" según el Diccionario de la RAE. 
tidianamente. Las dotes adquiridas son, fundamentalmente, las desarrolladas a través de procesos de educación formal, y su máximo horizonte es un título universitario de posgrado; pero vienen acompañadas de otro tipo de educación más especializada en cuestiones vinculadas al diseño de políticas públicas, la economía política, las relaciones internacionales y la estadística, entre otras. En cuanto a las dotes mixtas, son aquellas de corte básicamente instrumental; aunque tienen un fuerte componente fenotípico, pueden ser mejoradas gracias al entrenamiento o al aprendizaje, y son indispensables en la labor cotidiana del político con relación a su autocontrol, al manejo de la dinámica de grupos, y a la comunicación tanto en lo relativo a su faceta oral como a la imagen. ${ }^{31}$ En este sentido, la oratoria ha sido, desde la tradición clásica hasta el momento actual, una de las cualidades constantes atribuidas al buen político, como ha quedado suficientemente reflejado en las páginas anteriores. Aun hoy en día se afirma: "No se puede ser un buen político si no se sabe hablar... con un lenguaje que realmente comunique el pensamiento y que, además, lo matice y lo enriquezca con el dominio de las palabras". ${ }^{32}$ La experiencia se refiere al cursus honorum seguido, no sólo en lo relativo a su trayectoria estrictamente política sino en un sentido vital más amplio. En lo relativo al terreno no político, es relevante el desempeño de tareas profesionales tanto en la empresa privada y la administración pública, como en las labores de voluntariado realizadas con una dedicación intensa, en la medida de lo señalado por Helmut Schmidt o por Felipe González. El primero se refiere a la necesidad de que el político haya aprendido y ejercido un oficio, ${ }^{33}$ a fin de que sea factible lo que señala el segundo: "Uno tiene que saber entrar y salir de la responsabilidad institucional y política sin que se le acabe el horizonte... quien sólo sirva para ser diputado, es probable que tampoco sirva para eso". ${ }^{34}$ En el ámbito político cuentan los años de vida de partido vividos y las responsabilidades asumidas y luego los cargos alcanzados con énfasis en el nivel de los mismos, así como en el grado de especialización alcanzada. De modo que los políticos, en algunos países como Estados Unidos, Alemania o Chile, tienden a especializarse, a lo largo de su carrera parlamentaria, en determinadas políticas públicas, adscribiéndose a la comisión del ramo donde desempeñan su actividad de manera constante a lo largo de su vida

31 La claridad en la comunicación se destaca como la primera cualidad de un líder en Dewan y Myatt (2008).

Schmidt (2009: 198).

34 Manifestaciones en la presentación de la candidatura municipal del PSOE en Majadahonda. El País, Madrid, 19.02.11. 
política. Ello les permite alcanzar un cierto grado de conocimiento de los temas, así como de contactos con los expertos en los mismos. ${ }^{35}$

A diferencia de otros profesionales, el político tiene escaso control en la planificación de su carrera; aunque sí puede manipular en algunas ocasiones ciertos mecanismos institucionales, como las reglas electorales, o los reglamentos internos del partido o del Congreso, no por ello deja de ser incierto el resultado. Esto hace que la experiencia del político sea incluso más valiosa que en otras profesiones; el político experto procesa información políticamente relevante de forma más compleja y mucho más rápidamente que el novato. ${ }^{36}$ Sin embargo, la experiencia en sí misma no es remunerada ${ }^{37}$ y solamente satisface el componente psicológico del reconocimiento social, así como de toda ambición puesta en la reelección o en la continuidad de una carrera política en otros ámbitos.

La entrada en la política, tanto por la vía electoral como por la de la designación, permite no obstante al político evadir la satisfacción de alguno o de todos los requisitos de calidad. Contrariamente al ámbito de la administración pública de carrera, donde se incorpora el concurso de mérito para la selección del personal que conforma el cuerpo de servidores públicos, o para la selección de numerosos trabajos en los que se exige una entrevista o realizar una prueba que ponga de relieve habilidades o destrezas, en política la legitimidad electoral pareciera ser la condición no sólo necesaria sino también suficiente para investir al político de su función.

Sin embargo, desde la perspectiva de la calidad de los hombres y mujeres que se van a dedicar a la política como profesión, el sistema requiere incorporar mecanismos que aseguren las variables que se recogen en el Cuadro 2. Aunque el concurso de méritos no puede darse por razones obvias - chocaría con el derecho universal de cualquier individuo a ser candidato, y con una supuesta vigencia de patrones de igualdad,- 38 hay

35 Para la calidad de los diputados de los países andinos véase Cabezas (tesis doctoral en curso). Para el caso mexicano, un dato clave para obtener la calidad según Love (2009: 96) es haber ocupado antes un cargo de elección popular de cualquier tipo.

36 Funck (1997: 679-680).

37 Besley (2004: 197) defiende incrementos salariales en función del número de reelecciones logradas, como incentivos a un trabajo supuestamente bien hecho por parte del político. En este sentido, es interesante constatar la ausencia de incentivos propios en el ámbito salarial de la profesión de político, cuya actividad es, además, difícilmente mesurable, y cuando lo es puede ser irrelevante, como viene a ser el caso de la contabilidad de las sesiones parlamentarias a las que los diputados asisten.

38 Aunque esta igualdad es ficticia precisamente porque los mecanismos actuales de elección de candidatos ponen el acento en campañas electorales que son muy costosas y que pocos pueden afrontar, lo que enturbia el juego real de la democracia. La entrada en la política vinculada al 
dos elementos de la lógica en que funcionan los concursos ${ }^{39}$ que sí pueden incorporarse y estar presentes en el proceso de entrada en la política de quienes quieran hacer de la misma una profesión. En primer lugar, se trata de la exposición pública de un currículo que explicite el talento con relación a las dotes adquiridas y a la experiencia. Exhibición que puede llevarse a cabo muy fácilmente y sin costo alguno mediante su colocación en una página web. Paralelamente, los candidatos a políticos deben poner de relieve sus dotes innatas y mixtas, frente a un público interesado, participando en debates públicos con otros candidatos, o con actores sociales tanto en arenas donde estén presentes los medios de comunicación como en aquellas otras con académicos y otros profesionales, donde puedan ser interrogados y tengan la oportunidad de mostrar sus conocimientos y habilidades. La incorporación de criterios de concurso en la dirección señalada, es posible y deseable no sólo para quienes compiten en la arena electoral, sino también para aquellas personas que van a desarrollar su actividad en cualquiera de las otras dos arenas mencionadas: en los puestos de designación del Ejecutivo y de asesoría, y en los del propio partido.

Desde una perspectiva académica, todos los elementos que se puedan reunir para entender los diferentes niveles de calidad existentes en la profesionalización de los políticos en cualquier sistema político, resultan relativamente fáciles de enunciar, como lo prueba el cuadro 2, que resume lo dicho hasta ahora más los filtros de carácter concursal señalados para el proceso de entrada. El modelo propuesto tiene un carácter continuo de máximos y mínimos, pudiéndose dar en mayor o menos medida alguno de los elementos recogidos en el cuadro (o incluso no darse). La ventaja complementaria es que permite llevar a cabo un ejercicio de análisis tanto de las preferencias de la ciudadanía de uno u otro rasgo ${ }^{40}$ como del nivel de rigor incorporado en la entrada. Además, hay cierto acuerdo general respecto a cuáles son los elementos determinantes de la calidad de los políticos. ${ }^{41} \mathrm{Se}$

hecho de contar con dinero propio, o debida a un compromiso con un tercero que resulte fiduciario para afrontar la contienda electoral, es fuente de una profunda desigualdad.

39 "El concurso instituye una distinción no discriminatoria, puramente funcional, que se orienta al beneficio de todos y constituye, por lo tanto, el envés de un privilegio." Rosanvallon (2010: 91). Si bien Funk (1997) puso de manifiesto cómo los rasgos cualitativos de los candidatos eran más positivamente valorados por los electores con mayores niveles de información política que los rasgos carismáticos de cercanía o simpatía, los debates, que seguramente sólo serían seguidos por quienes tienen interés explícito en seguir las cuestiones políticas, podrían reforzar solamente la opinión en dicho grupo de personas. Ese escenario, por otra parte, se da incluso en aquellos espacios definidos por escándalos políticos. La misma Funk (1996) lo avala en otro estudio en que tiene en cuenta la infidelidad matrimonial y la evasión de impuestos.

Véase la discusión al respecto en Martínez Rosón (2008). 
trata de un modelo de tipo informal, en la medida en que "induce conclusiones a partir de evidencias empíricas dispersas que después forman parte del fenómeno" 42 de la calidad del político. Es por ello que el presente es un modelo que, como tal, simplifica a la vez que nos aproxima al problema de la calidad del político, que no necesariamente implica una correlación muy estrecha entre calidad y profesión. De ahí que el modelo tenga como objetivo señalar con claridad y atender al mismo tiempo los problemas "que hay que evitar y las oportunidades que pueden aprovecharse". ${ }^{43}$ Fuera de este esquema propositivo ha quedado toda alusión al necesario componente ético. En la medida en que la honestidad, así como el compromiso con los valores democráticos del político, se ejercen día a día bajo la autoridad de procesos de rendición de cuentas y de control del cumplimiento del código de ética de la institución en que desempeña su cargo, se entiende que son elementos exógenos del propio sistema político que afectan por igual a toda la clase política.

Cuadro 2. La calidad del político profesional

\begin{tabular}{cll}
\hline \multirow{2}{*}{ Dedicación a tiempo completo } & \\
\hline \multirow{2}{*}{ Talento } & Dotes innatas & Fenotipo, inteligencia, energía vital \\
\cline { 2 - 3 } & Dotes mixtas & Inteligencia emocional, comunicación (oratoria y telegenia) \\
\cline { 2 - 3 } & Dotes adquiridas & Educación formal, educación especializada \\
\hline \multirow{2}{*}{ Experiencia } & Actividad fuera de la política & Actividades de voluntariado, vida laboral \\
\cline { 2 - 3 } & Actividad política & $\begin{array}{l}\text { Vida partidista, cargos públicos desempeñados, grado } \\
\text { de especialización }\end{array}$ \\
\hline
\end{tabular}

Fuente: elaboración propia.

El reto consiste ahora en volver operativos estos elementos, como variables y en la construcción de la correspondiente matriz que ayude a la comprensión del fenómeno y a dar con la forma en que pueden intervenir como factores explicativos de la vida política y de su relación con la calidad de la misma. La calidad del político, en los extremos aquí apuntados, no asegura por sí misma el éxito de la gestión, y hay evidencias de que políticos situados en las antípodas del esquema aquí propuesto han conseguido resultados notables, lo cual puede llevar al desaliento intelectual. Se trata, por consiguiente, de una propuesta con un alto grado normativo y cuya bondad debe ser probada con datos agregados y con una buena dosis de coraje cívico e intelectual que además se deje guiar por el sentido común.

\footnotetext{
42 López Montiel (2006: 65).

43 King, Keohane y Verba (2000: 61).
} 


\section{La formación de los profesionales de la política}

El profesional de la política se mueve en el seno de un cuadrado cuyos lados son la remuneración, la dedicación, la vocación y la ambición. Ahora bien, ¿qué significado tiene que un presidente diga que su tarea es la más difícil de la historia? ${ }^{44}$ Se trata de alguien que, por definición, ha alcanzado la cúspide de su carrera, por lo que la vocación y la ambición están satisfechas, su dedicación ocupa todo su tiempo, y la remuneración no es desdeñable, ni en el sentido económico ni en lo relativo al capital simbólico acumulado. Esta figura geométrica, situada en un plano, adquiere forma espacial cuando se añade la preocupación por la calidad del político profesional, abordada en la sección anterior. Se trata de un requisito, en clave de competencia, que se introduce en el mundo de la política por cuanto la actividad desempeñada, en su proceso de profesionalización, requiere respuestas bien fundamentadas, que a su vez demandan ciertos niveles de conocimiento y de experiencia, los cuales se agregan a las características innatas de la persona dedicada a la política en clave de talento. Se trata de que los políticos estén "preparados". 45 Pero ¿qué significa estar preparados, ser competentes? La competencia, ${ }^{46}$ por consiguiente, tiene dos componentes: uno de carácter estático y que viene dado por lo que aquí denomino talento, y otro de carácter dinámico, que supone un proceso ininterrumpido de formación. Ambos forman parte del capital político personal que Bourdieu llama "de reconocimiento", pues contribuye a la notoriedad del político, y en parte constituyen también el capital político personal carismático, "heroico" o "profético" ${ }^{47} \mathrm{El}$ talento comprende cualidades individuales psicológicas y estrictamente biológicas; engloba factores psicológicos y otros de componente genético o neurológico, y todos ellos determinan al político en su perfil de reconocido prestigio así como carismático. El talen-

44 Alan García, en un discurso dirigido al FMI el 17 de agosto de 1986, afirmaba: "Ser presidente es quizá la más difícil profesión de la historia del Perú".

45 El ex vicepresidente del gobierno español, Alfonso Guerra, señaló que "España está preparada para cualquier líder, hombre o mujer", si bien precisó que "lo que hace falta es que los líderes estén preparados". Luis R. Aizpeolea, “El apoyo de Chacón a las primarias desata el debate de la sucesión", El País, Madrid, 24.02.11.

46 Joignant (2011: 52) señala que "la competencia política es extraordinariamente compleja puesto que suele conllevar un lenguaje de capacidades y, por tanto de desigualdades, que, de no mediar un control lógico, puede fácilmente desembocar en la naturalización de tal o cual tipo de capacidad o habilidad de acuerdo con una tácita filosofía de la esencia innata y no como el resultado de la apropiación de capital, el que puede ser adquirido o heredado (o una combinación de ambas formas)".

47 Bourdieu (2001: 244). 
to es un tipo de competencia que integra cualidades que se recogen bajo la rúbrica genérica de la inteligencia y de la capacidad de conocimiento. ${ }^{48}$ Estos tienen que ver con habilidades que potencien la agilidad mental, la credibilidad, la capacidad de síntesis, la capacidad oratoria, la toma de decisiones, el trabajo en equipo, el diálogo y la argumentación, la búsqueda de compromisos, la generación de confianza, la adaptabilidad al medio y a los otros, y la prudencia. Pero también se trata del coraje, de la energía, del control del pánico y de las emociones en general, así como de la contención de la agresividad. Sin embargo, sobra decir que no todos los políticos reúnen en su persona la totalidad de estos rasgos característicos; muchos de ellos pueden ser útiles en determinados contextos culturales o espacios políticos, pero no en otros; pueden ser oportunos en un momento, pero no en el siguiente. ${ }^{49}$ Como he señalado, el segundo elemento integrante de la competencia tiene que ver con el nivel formativo del político, que complementa los atributos individuales recién enunciados y se integra en la propia trayectoria política o cursus honorum. La experiencia, en estricto sentido, se añade a la configuración de cualquier carrera política, contribuyendo enormemente a dotarla de capital simbólico. Los datos sobre la educación formal son abundantemente conocidos, así como la orientación seguida, en éste o aquel país, hacia la tecnopolítica, ${ }^{50}$ orientación que ha generado un esquema que no es de ahora y por el que se produce una división de trabajo entre políticos generalistas y otros de naturaleza técnica. ${ }^{51} \mathrm{~A}$ pesar de que en algún momento pareció que el mundo universitario se tomaba en serio la tarea de formar políticos, ${ }^{52}$ no hay un proceso canónico universal de formación de políticos. En los regímenes que tienen un mínimo interés

48 Funk (1999: 702).

49 Keohane (2005: 709).

50 Es el caso de Chile en América Latina (véase Delamaza, 2011).

51 Aquí defiendo el hecho de que ambos son políticos profesionales, una posición diferente a la de Joignant (2011: 74), quien menciona como categorías diferentes a "los hombres de partido y los políticos profesionales [que] constituyen verdaderos agentes generalistas o todoterreno, puesto que no existen áreas gubernamentales vedadas para ellos, lo que deja de ser cierto para el pequeño grupo tecnocrático". La inexistencia de servicios civiles de carrera puede estar en la base de esta confusión.

La Facultad de Ciencias Políticas y Económicas, sección Políticas, de la Universidad de Madrid se creó a raíz del final de la Guerra Civil teniendo como objetivo fundamental la formación de cuadros del nuevo régimen político. Esta inquietud, aunque en un país democrático como Estados Unidos, también allí estuvo presente en el mismo tiempo como lo prueba la siguiente cita: "Puede llegar un momento cuando el éxito de una facultad y particularmente de un departamento de ciencia política será medido por la proporción de sus egresados que lleguen a ser políticos en activo" [traducción del original del autor]. William E. Moster (1944). "Wanted: New Type Politicians". National Municipal Review, 33, p. 237. Citado en Paige (1977: 207). 
en la formación de su clase política, hay básicamente dos sendas por las que transitan todos los que quieren desarrollar una carrera política, si bien dichas sendas no son divergentes, pues en algún momento se pueden cruzar. Una es la que dibujan los propios partidos políticos a través de sus escuelas de formación (escuelas muchas veces potenciadas a la vez que homologadas por su pertenencia a redes internacionales, las cuales tienen una estructura permanente y desarrollan programas siguiendo determinada racionalidad), o por medio de los diversos mecanismos que ponen en juego para capacitar a sus cuadros de manera eventual, episódica y poco institucionalizada. Pero los partidos políticos que tienen programas de formación, apenas si se preocupan por capacitar en profundidad a sus miembros, ya que están ahogados por la urgencia del día a día y obsesionados con la prédica del peso de las relaciones públicas, las técnicas de comunicación y la telegenia, además del denominador común, presente casi siempre, constituido por cuestiones de legislación y normativas. Materias como la demoscopia, o como la del funcionamiento de las instituciones en perspectiva comparada, y el amplio abanico de la lógica del desarrollo de las políticas públicas, suelen estar ausentes, por no mencionar el recurrente olvido de cuestiones como historia política contemporánea, economía política, relaciones internacionales, conceptos políticos básicos o teoría política.

La segunda senda es la que siguen de forma individual las personas que buscan primeramente obtener una carrera universitaria que luego les facilite la entrada en la política, bien por haber obtenido una formación de muy alto nivel o por disponer de contactos que les proyectan hacia el mundo de la política. Viene a ser el caso de las universidades tradicionales en el mundo anglosajón y de sus escuelas de gobierno o similares, o de las grandes escuelas en el caso francés. ${ }^{53}$ En otro ámbito, se destaca asimismo, en los últimos tiempos, la floración de numerosos cursos de especialización, o de máster profesional, sobre campañas electorales, comunicación política y marketing político, impartidos por un claustro formado por políticos con notable experiencia y por académicos de las ciencias sociales. Este tipo de formación no comporta un carácter totalmente autodidacta, por cuanto trata de programas estructurados con base, los primeros, en una gran tradición de relación con el servicio público y en el hecho de que en los mismos coinciden personas con intereses parecidos que terminan generando un proceso virtuoso de socialización. Sin embargo, el hecho de que se desvinculen orgánicamente de los partidos políticos, acentúa una

53 Me refiero al Instituto de Ciencias Políticas y a la Escuela Nacional de Administración. (Véase Bordieu, 1989 y 2001: 217-224.) 
forma de hacer política basada en candidatos individuales con el consiguiente impacto en el propio sistema político.

La tarea de formación del político no sólo consiste en un proceso de crecimiento interno de habilidades y de conocimiento; también estriba en la capacidad de establecer vínculos con el mundo externo de técnicos e intelectuales. Los técnicos pueden ser incorporados a la política "para elaborar programas orgánicos que le lleven esperanzas serias a la colectividad" ${ }^{54}$ Esta permanente apertura "al mundo exterior" que comporta la pérdida del monopolio de la profesión, es, finalmente, un buen antídoto contra la endogamia y una oportunidad para hacer socialmente más porosa a la clase política.

Por otra parte, la incidencia de factores externos, como los procesos de integración regional en los países miembros, son asimismo un agente de indudable influencia a la hora de desarrollar, en los nuevos políticos, determinados perfiles necesariamente más afines a un escenario que requiere habilidades diferentes y un entrenamiento técnico más sofisticado. ${ }^{55}$

\section{Conclusiones}

Este artículo incursiona en un terreno muy particular de la representación política: el de los profesionales de la política. Un grupo de hombres y mujeres sometidos a la tensión, que a veces se vuelve insoportable, entre su papel como representantes y su papel como gestores; entre aspectos específicamente políticos y otros estimados como más técnicos. El hilo conductor de nuestro escrito ha sido la idea de que la calidad de los políticos afecta a la calidad de la política, cuyo carácter es multidimensional. En la medida en que los políticos de hoy son profesionales, el estudio ha girado lo mismo en torno a cuestiones relativas a la forma en que estos profesionales entran en la política y pueden ser definidos analíticamente, que a la manera en que pueden ser evaluados en virtud de esta definición; es decir: en la medida en que satisfacen en mayor o menor grado los requisitos propios de un político de calidad. En este escenario se pone especial énfasis en la parte formativa de los políticos, un aspecto descuidado por la academia y solamente abordado por las fundaciones partidistas y las oficinas de cooperación.

54 Caldera (1963: 439). 
Este artículo reivindica a los políticos profesionales, que hoy son objeto de una crítica muy aguda por parte de diversos sectores de la sociedad, tanto desde una perspectiva normativa como, sobre todo, por la circunstancia de que la profesionalización de la política es un hecho incuestionable, cuyo estudio se hace ineludible para entender uno de los aspectos en que se presenta en la actualidad la representación política. Cuestiones vinculadas a la forma de entrada en la política, a su continuidad en la misma y a la manera en que se sale (y a dónde se va), se entrelazan con aspectos de la propia carrera política, que, como aquí se defiende, es una cuestión de dedicación, de tiempo para acumular experiencia, y de la remuneración recibida por una tarea que requiere determinados niveles de talento.

Los políticos profesionales, aunque tienen en muchos casos el monopolio de la representación política, están sometidos a avatares que no tienen otras profesiones, debido a la propia incertidumbre que define la vida democrática, sometida al albur de los momentos electorales, de la pérdida de confianza y de los diferentes procesos de rendición de cuentas. De hecho, este sistema, que trae consigo la renovación casi permanente, comporta también una seria constricción en pro de un mecanismo que mantenga a los mejores en la arena política, con la consiguiente incidencia en la calidad de los políticos. Sin embargo, al igual que sucede en otras profesiones, los políticos requieren someterse a mecanismos de formación que, en cierta medida, son específicos. Incluso su modo de entrada, tan determinado por la confianza del público, puede tamizarse gracias a determinados instrumentos que introduzcan algún componente de calidad en el ingreso en la lógica de la representación política. En este sentido, la exposición pública de sus méritos, así como de su trayectoria, y el debate previo entre diferentes candidatos y con distintos sectores sociales, pueden convertirse en venturosos mecanismos de selección con respecto a la entrada en la política. El éxito o el fracaso de un político están condicionados por una variada gama de limitaciones externas, muchas veces de carácter estructural; de ahí que en este artículo no se ponga el acento en los outputs, aunque ello no debe ser una excusa para no abordar, como aquí se ha pretendido, las condiciones ideales que a priori pueden determinar la calidad de los políticos. 


\section{Bibliografía}

Aguilera, Carolina y Claudio Fuentes, 2011, “Elites y asesoría experta en Chile: comisiones y políticas públicas en el gobierno de Bachelet", en Alfredo Joignant y Pedro Güell (eds.), Notables, tecnócratas y mandarines. Elementos de sociología de las elites en Chile (1990-2010), Santiago de Chile, Ediciones Universidad Diego Portales, pp. 127-151.

Alcántara, Manuel, 2012, El oficio de político, Madrid, Tecnos.

Bermeo, Nancy, 2003, Ordinary People in Extraordinary Times. The Citizenry and the Breakdown of Democracy, Princeton, Princeton University Press.

Bermeo, Nancy, 2003a, "Ministerial Elites in Southern Europe: Continuities, Changes and Comparison", en Pedro Tavares de Almeida, António Costa Pinto y Nancy Bermeo (eds), Who Governs Southern Europe? Regimen Change and Ministerial Recruitment 1850-2000, Londres, Frank Cass, pp. 205-227.

Besley, Timothy, 2004, "Paying Politicians: Theory and Evidence", Journal of the European Economic Association, vol. 2, núms, 2 y 3, pp. 193-215.

Bourdieu, Pierre, 1989, La noblesse d'état. Grandes écoles et esprit de corps, París, Les Éditions de Minut.

Bourdieu, Pierre, 2001, Langage et pouvoir symbolique, París, Éditions Fayard.

Cabezas, Lina (en curso), La profesionalización de las elites parlamentarias en Bolivia, Colombia, Ecuador y Perú, tesis doctoral, Universidad de Salamanca.

Caldera, Rafael, 1963, Políticos y técnicos, Caracas, Fracción parlamentaria del partido socialcristiano Copei.

Cardenal, Ernesto, 2004, La revolución perdida, Madrid, Editorial Trotta.

Delamaza, Gonzalo, 2011, “Elitismo democrático, líderes civiles y tecnopolítica en la reconfiguración de las elites políticas", en Alfredo Joignant y Pedro Güell (eds.), Notables, tecnócratas y mandarines. Elementos de sociología de las elites en Chile (19902010), Santiago de Chile, Ediciones Universidad Diego Portales, pp. 77-108.

Dewan, Torun y David P. Myatt, 2008, “The Qualities of Leadership: Direction, Communication, and Obfuscation", American Political Science Review, vol. 102, núm. 3, pp. 351-368. 
Diamond, Larry y Leonardo Morlino (eds.), 2005, Assesing the Quality of Democracy, Baltimore, The Johns Hopkins University Press.

Diamond, Larry y Leonardo Morlino, 2005a, "Introduction", en Larry Diamond y Leonardo Morlino (eds.), 2005, Assesing the Quality of Democracy, Baltimore, The Johns Hopkins University Press.

DiRenzo, Gordon J., 1967, "Professional Politicians and Personality Structures", The American Journal of Sociology, vol. 73, núm. 2, pp. 217-225.

Eldersveld, Samuel J., 1989, Political Elites in Modern Societies. Empirical Research and Democratic Theory, Ann Arbor, The University of Michigan Press.

Fowler, Linda L. y Robert D. McClure, 1989, Political Ambition. Who Decides to Run for Congress, New Haven, Yale University Press.

Funk, Carolyn L., 1996, “The Impact of Scandal on Candidate Evaluations: An Experimental Test of the Role of Candidate Traits", Political Behavior, vol. 18, núm. 1 , pp. 1-24.

Katz, Milton, 1966, The Things that are Caesar's, Nueva York, Alfred A. Knopf.

Joignant, Alfredo, 2011, “Tecnócratas, technopols y dirigentes de partido: tipos de agentes y especies de capital en las elites gubernamentales de la Concertación (1990-2010)", en Alfredo Joignant y Pedro Güell (eds.), Notables, tecnócratas y mandarines. Elementos de sociología de las elites en Chile (1990-2010), Santiago de Chile, Ediciones Universidad Diego Portales, pp. 47-76.

Keohane, Nanneri O., 2005, “On Leadership”, Perspectives on Politics, vol. 3, núm. 4, pp. 705-722.

King, Gary, Robert O'Keohane y Sydney Verba, 2000, El diseño de la investigación social. La influencia en los estudios cualitativos, Madrid, Alianza.

Levine, Daniel y José Enrique Molina (eds.), 2011, The Quality of Democracy in Latin America, Boulder, Lynne Rienner.

López Montiel, Gustavo, 2006, “Modelos formales en ciencia política: ¿alternativas en la construcción y validación de teoría?", en Víctor Alarcón Olguín (coord.), Metodologías para el análisis político. Enfoques, procesos e instituciones, México, UAM y Plaza y Valdés Editores, pp. 60-72. 
Love, Gregory, 2009, “Competir y ganar: calidad de los candidatos en las elecciones legislativas de 2006 en México", Política y Gobierno, volumen temático, México, CIDE, pp. 77-100.

Martínez Rosón, María del Mar, 2008, La carrera política de los parlamentarios costarricenses, hondureños y salvadoreños: selección y ambición política, tesis doctoral, Universidad de Salamanca.

Norris, Pippa, 1997, "Conclusions: comparing passages to power", en Pippa Norris (ed.), Passages to Power. Legislative recruitment in advanced democracies, Cambridge, Cambridge University Press, pp. 209-231.

O'Donnell, Guillermo; Jorge Vargas, Osvaldo Iazzetta (eds.), 2004, The Quality of Democracy: Theory and Applications, Notre Dame, University of Notre Dame Press.

Paige, Glenn D., 1977, The Scientific Study of Political Leadership, Nueva York, Free Press.

Pasquino, Gianfranco, 2010, “El parlamentarismo en Europa Meridional: estudio del modelo italiano", presentado en el Seminario Internacional El parlamentarismo europeo y el presidencialismo latinoamericano cara a cara, organizado por la Fundación Manuel Jiménez Abad, Zaragoza, 17 y 18 de marzo.

Powell, G. Bingham Jr., 2005, “The Chain of Responsiveness”, en Larry Diamond y Leonardo Morlino (eds.), Assesing the Quality of Democracy, Baltimore, The Johns Hopkins University Press, pp. 62-76.

Rosanvallon, Pierre, 2010, La legitimidad democrática: imparcialidad, reflexividad y proximidad, Barcelona, Paidós.

Sabl, Andrew, 2002, Ruling Passions. Political Offices and Democratic Ethics, Princeton, Princeton University Press.

Schmidt, Helmut, 2009, Fuera de servicio. Balance de una vida, Madrid, Icaria-Fride.

Schmitter, Phillippe C., 2010, "Twenty-five Years, Fifteen Findings", Journal of Democracy, vol. 21, núm.1.

Schumpeter, Joseph A., 1947, Capitalism, Socialism and Democracy, $2^{\mathrm{a}}$ ed., Nueva York, Harper \& Brothers Pub.Vargas Llosa, Mario, 2001, Literatura y política, México, Ariel.

Recibido el 13 de diciembre de 2011

Aceptado el 10 de octubre de 2012 